\title{
La trayectoria política de Toribio Montes en América, 1804-1818
}

Resumen: Al encargarse de la presidencia de la Audiencia de Quito en 1812, Toribio Montes se convirtió en uno de los más caracterizados defensores en el continente de un modelo de pacificación no punitivo, basado en el perdón, el olvido y la reconciliación. ¿En qué condiciones se forjaron estas sólidas convicciones políticas? Para comprenderlo, el artículo analiza la experiencia de gobierno de Montes en América - desde su llegada a Puerto Rico como capitán general en 1804 hasta su lento viaje de despedida del Nuevo Reino en 1818-, y la confronta con la de otros dos destacados mandatarios españoles del virreinato de Santa Fe [Antonio Amar y Juan Sámano].

Palabras clave: crisis de la monarquía, revolución, independencia, pacificación, restauración, Nuevo Reino de Granada.

\section{Toribio Montes' political trajectory in America, 1804-1818}

Abstract: As president of the Audience of Quito in 1812, Toribio Montes became one of the continent's most distinguished defenders of a model of non-punitive pacification, based on forgiveness, forgetfulness, and reconciliation. Under what conditions were these strong political convictions forged? To understand this, the article analyzes Montes' experience in government in America, from his arrival in Puerto Rico as captain general in 1804 to his slow farewell trip to the New Kingdom in 1818, contrasting these experiences with those of two other known Spanish leaders of the viceroyalty of Santa Fe: Antonio Amar and Juan Sámano.

Keywords: monarchy crisis, revolution, independence, pacification, restoration, New Kingdom of Granada.

\section{A trajetória política de Toribio Montes na América, 1804-1818}

Resumo: Quando tomou posse da presidência da Audiência de Quito em 1812, Toribio Montes tornou-se um dos mais destacados defensores no continente de um modelo não-punitivo de pacificação, baseado no perdão, no esquecimento e na reconciliação. Em que condições foram forjadas essas fortes convicções políticas? Para responder a essa indagação, o artigo analisa a experiência do governo de Montes na América - desde sua chegada a Porto Rico como capitão-general em 1804 até sua lenta viagem de despedida do Novo Reino em 1818 - e a confronta com a de outros dois líderes espanhóis do vice-reino de Santa Fé [Antonio Amar e Juan Sámano].

Palavras-chave: crise da monarquia, revolução, independência, pacificação, restauração, Novo Reino de Granada.

Cómo citar este artículo: Daniel Gutiérrez Ardila, "La trayectoria política de Toribio Montes en América, 1804-1818”, Trashumante. Revista Americana de Historia Social 16 [2020]: 104-123.

DOI: 10.17533/udea.trahs.n16a06

Fecha de recepción: 11 de junio de 2019

Fecha de aprobación: 25 de marzo de 2020

Daniel Gutiérrez Ardila: Doctor en historia por la Universidad París I y docente investigador del Centro de Estudios en Historia [CEHIS] de la Universidad Externado de Colombia.

Correo electrónico: danielgutierrezardila@gmail.com 


\section{La trayectoria política de Toribio Montes en América, 1804-1818}

Daniel Gutiérrez Ardila

\section{De Orán a Quito}

T

oribio Montes Caloca y Pérez nació en un pueblo de las montañas de Santander en 1749.A los 15 años se alistó en el ejército, sirviendo primero en Orán y luego en la expedición contra Argel (1775), el bloqueo de Gibraltar (1779), la reconquista de Menorca (1781) y las guerras contra la república francesa (1793) y Portugal (1801). Esas cuatro décadas en las filas españolas le permitieron ascender desde el rango de cadete hasta el de mariscal de campo y ser nombrado capitán general de Puerto Rico el 26 de abril de $1804 .^{1}$

En el mes de diciembre de ese año, Toribio Montes se hizo cargo del gobierno de la isla. Desde el comienzo enfrentó una situación muy compleja por la inminente guerra con Gran Bretaña y por el recelo que producía un eventual sitio de San Juan, pues la plaza estaba exhausta de caudales y víveres y muy escasa en recursos defensivos. ${ }^{2}$ A los cuatro meses de residir en Puerto Rico, Montes se refirió a la indigencia de las cajas reales en las que había únicamente diez mil pesos. Sin embargo, con el "espíritu de un montañés que a nada teme", como anunciaría él mismo, arrostró las dificultades, valiéndose de "arbitrios y medios extraordinarios para sostener los crecidos e indispensables gastos” de la isla. Permitió, por ejemplo, el comercio de neutrales, que autorizaba a los buques de las colonias amigas de España a cargar en Puerto Rico y aliviaba a los hacendados, al proveerlos de dinero en Veracruz o La Habana. Montes tomó la decisión sin muchos miramientos por los reglamentos monopolísticos, pues consideraba con recio pragmatismo que la preservación de la isla exigía medios y, en particular, derechos procedentes del

1. Enrique Muñoz Larrea, "El teniente general Don Toribio Montes Caloca y Pérez", Boletín de la Academia Nacional de Historia LXXXVIII.184 (2010): 175-183.

2. Toribio Montes, "Carta a Juan Vicente Arce”, San Juan, 22 de enero de 1805. AGPR, San Juan, Fondo Capitanía General, t. 26. 
comercio de importación y exportación. Con todo, se trataba de paliativos, habida cuenta de la escasez de las "producciones coloniales". 3

Al cumplir año y medio en el cargo de capitán general, Montes seguía considerando que la situación de Puerto Rico era muy arriesgada por falta de medios de subsistencia y declaraba que su suerte dependía de los auxilios que pudieran prestarle las demás posesiones del rey en América. ${ }^{4}$ Precisamente, entabló para el efecto correspondencia con las principales autoridades de las posesiones imperiales en el continente. El virrey del Nuevo Reino, Antonio Amar, respondió las instancias de Montes autorizando la entrada a Cartagena y Santa Marta de "una o dos embarcaciones" procedentes de Puerto Rico con frutos del país. Poco pudo hacer, no obstante, con respecto a los cuatrocientos mil pesos que el capitán general de Puerto Rico le pidió en préstamo en 1805. También desde Caracas se le solicitaba con insistencia medio millón, pero no podía satisfacer tales requerimientos cuando el ministerio había girado "gruesas libranzas" contra las cajas de Santa Fe justo antes de la declaración de guerra contra Inglaterra. ${ }^{6}$

La solicitud acuciante de fondos por parte de Montes a Antonio Amar se fue transformando poco a poco en una relación epistolar más compleja que dio lugar a intercambio de noticias, porque a las costas del Nuevo Reino apenas llegaban estas y porque a los comerciantes del virreinato les estaba prohibido "el comercio a colonias". Ni siquiera se recibía regularmente en el territorio neogranadino la correspondencia de la metrópoli en razón de la guerra, así que se desconocían las circunstancias particulares de esta e incluso el nombre de sus diversas autoridades, pues ni con la guía de forasteros se contaba. ${ }^{7}$ En marcado contraste, Montes adquirió una imprenta para publicar una gaceta dos veces por semana e instruyó a los tenientes a guerra de la isla para que franquearan su lectura al vecindario y aun para que la prestasen a cualquiera que desease tomar apuntes. ${ }^{8}$

A mediados de 1807 Toribio Montes escribió al virrey de Santa Fe una dramática carta en la que anunciaba que desde hacía 49 meses (esto es, ¡cuatro años!) tropa y empleados estaban a media paga. En consecuencia, seguía promoviendo el comercio de neutrales para aliviar un tanto las arcas puertorriqueñas y solicitaba de nuevo que se permitiera atracar a los buques comprometidos en

3. Toribio Montes, "Carta a Juan Vicente Arce”, San Juan, 12 de mayo de 1805. AGPR, San Juan, Fondo Capitanía General, t. 26.

4. Toribio Montes, "Carta a Juan Vicente Arce", San Juan, 13 de julio de 1806. AGPR, San Juan, Fondo Capitanía General, t. 26.

5. Antonio Amar, "Carta a Toribio Montes", Santa Fe, 15 de febrero de 1806. AGPR, San Juan, Fondo Capitanía General, t. 33.

6. Antonio Amar, "Carta a Toribio Montes", Santa Fe, 9 de mayo de 1805. AGPR, San Juan, Fondo Capitanía General, t. 33.

7. Antonio Amar, "Carta a Toribio Montes", Santa Fe, 6 de julio y 21 de agosto de 1805. AGPR, San Juan, Fondo Capitanía General, t. 33.

8. Miguel B. Márquez, "Sobre los comienzos del periodismo en Puerto Rico", Ámbitos. Revista Andaluza de Comunicación 3-4 (1999-2000): 205-219. 
aquellas operaciones en Cartagena, Santa Marta y Portobelo. Se trataba de un recurso indispensable, porque ninguna posesión española le facilitaba socorros por temor a una interceptación de los ingleses, que apresaban "hasta los buques neutrales". " El virrey Amar reiteró la incapacidad en que se hallaba de socorrerlo, indicando que cualquier transferencia de fondos comprometería la seguridad del Nuevo Reino. ${ }^{10}$

A finales de 1809 Amar dio cuenta a Montes de la creación y corta vida de una junta en Quito, así como de la resistencia que opusieron al movimiento las provincias de Popayán al norte, y Cuenca y Guayaquil al sur. ${ }^{11}$ Se trataba de información de primera importancia para el saliente capitán general, que había sido nombrado subinspector de las tropas veteranas de milicias de infantería y caballería del Perú. Pero mientras Amar sufría un serio desafio a su autoridad y veía comprometida la estabilidad del Nuevo Reino, Montes tenía razones para celebrar: en alianza con los ingleses había despachado expediciones militares a Santo Domingo que destruyeron en el mes de julio de 1809 el régimen francés en la isla y recuperaron para la Corona la parte oriental de La Española. ${ }^{12}$

Montes pasó entonces a Lima, ciudad en la que permaneció durante un año y nueve meses antes de embarcarse rumbo a la Audiencia de Quito como flamante presidente de ella y como comandante de una expedición costeada por el Consulado de Lima para aniquilar el movimiento revolucionario que irradiaba desde la principal ciudad de la jurisdicción. ${ }^{13}$ Montes llegó a Guayaquil el 21 de junio de 1812 y no tardó en entrar en campaña; viéndose coronados sus esfuerzos con éxito a comienzos de noviembre, cuando se adueñó de Quito. ${ }^{14}$ Su llegada generó tal pánico que la ciudad quedó vacía, habiéndose ausentado hasta las religiosas de clausura y el obispo José Cuero y Caicedo (muy comprometido, es verdad, con la revolución). ${ }^{15}$

9. Toribio Montes, “Carta a Antonio Amar”, San Juan, 26 de junio de 1807. AGPR, San Juan, Fondo Capitanía General, t. 33; Toribio Montes, "Carta a Víctor Salcedo”, San Juan, 15 de julio de 1807. AGPR, San Juan, Fondo Capitanía General, t. 33

10. Antonio Amar, "Carta a Toribio Montes", Santa Fe, 18 de marzo de 1808. AGPR, San Juan, Fondo Capitanía General, t. 33.

11. Antonio Amar, “Carta a Toribio Montes”, Santa Fe, 18 de diciembre de 1809. AGPR, San Juan, Fondo Capitanía General, t. 33.

12. Graham Townsend Nessler, "A Failed Emancipation? The Struggle for Freedom in Hispaniola during the Haitian Revolution, 1789-1809" (Tesis de doctorado en Historia, University of Michigan, 2011) 345-352.

13. Muñoz Larrea, "El nombramiento de Montes como presidente de la Audiencia de Quito", Quito, 1 de noviembre de 1811. AGI, Sevilla, Quito, 218.

14. José Manuel Restrepo, Historia de la revolución de la República de Colombia en la América Meridional, t. 1 (Besanzón: Imprenta de José Jacquin, 1858) 163-173; Pedro Fermín Cevallos, Resumen de la historia del Ecuador desde su origen hasta 1845, t. 3 (Guayaquil: Imprenta de la Nación, 1886) 137-162.

15. Toribio Montes,"Carta al obispo José Cuero y Caicedo", Quito, 15 de noviembre de 1812.AGI, Sevilla, Quito, 222, [s. f.]. 
En suma, al hacerse cargo de la presidencia de la Audiencia de Quito, Toribio Montes era un militar de avanzada edad (superaba los 60 años) con una rica experiencia en el norte de África, Europa y América. Haber gobernado Puerto Rico en tiempos de la guerra con Inglaterra y de la crisis de la monarquía contribuyó en gran medida a la cristalización de un método de gobierno marcado por la autosuficiencia, la carencia de medios y la colaboración permanente con los habitantes de la isla. Como se ha visto, la indigencia del erario y lo apurado de las circunstancias llevaron a Montes a introducir innovaciones comerciales, cuyo propósito primordial era la preservación de la integridad del imperio. En ese sentido, el contraste con Antonio Amar es supremamente ilustrativo, pues el virrey de Santa Fe optó por una vía opuesta, caracterizada por el mantenimiento de un monopolio comercial impotente y por una desinformación mal controlada. ${ }^{16} \mathrm{La}$ primera decisión significó un drástico empobrecimiento del erario, la segunda coartó los medios disponibles para combatir el inconformismo y las suspicacias generadas por la política de aislamiento.

\section{En Quito}

La conducta de Toribio Montes en Quito llama la atención por su tacto y moderación. Para apreciar este rasgo en sus debidas proporciones debe recordarse que el 2 de agosto de 1810 varios promotores de la primera junta instalada en la ciudad fueron cruelmente asesinados en sus calabozos, mientras los soldados realistas masacraban a numerosas gentes del pueblo. Luego de la instalación del segundo gobierno revolucionario de Quito, la prolongada guerra contra las provincias realistas de Cuenca y Guayaquil había generado tal irritación que en junio de 1812 un motín popular en la capital culminó con la muerte del expresidente de la Audiencia, conde Ruiz de Castilla, a pesar de que vivía retirado de los negocios. ${ }^{17}$

Y, sin embargo, las políticas de pacificación adoptadas por Montes nada tienen que ver con lo sucedido posteriormente en el Nuevo Reino luego de la llegada del Ejército de Costa Firme ${ }^{18}$ ni con las experiencias de pacificación emprendidas

16. Véase Jorge Orlando Melo, ed., Escritos económicos. Antonio de Narváez, José Ignacio de Pombo (Bogotá: Banco de la República, 2010); Anthony McFarlane, Colombia antes de la independencia. Economía, sociedad y política bajo el dominio borbón (Bogotá: Banco de la República / El Áncora Editores, 1997) 440-455; Alfonso Múnera, El fracaso de la nación. Región, clase y raza en el Caribe colombiano (1717-1821) (Bogotá: Banco de la República / El Áncora Editores, 1998) 111-148; Sergio Mejía Macía, Cartografía en la tormenta. Los mapas de Vicente Talledo y Rivera (1758-1820) entre España y el Nuevo Reino de Granada en la Era de las Revoluciones [En prensa]; José Antonio Amaya e Iván Felipe Suárez, Ojos en el cielo, pies en la Tierra. Mapas, libros e instrumentos en la vida del Sabio Caldas (Bogotá: Museo Nacional de Colombia, 2018) 64-83.

17. Restrepo 62-67 y 165-166.

18. Antonio Rodríguez Villa, El teniente general don Pablo Morillo, primer conde de Cartagena, marqués de la Puerta (1778-1837), 4 vols. (Madrid: Establecimiento tipográfico de Fortanet, 1910); Restrepo; Oswaldo Díaz Díaz, La Reconquista española, 2 vols. (Bogotá: Academia Colombiana de Historia, 1964); Juan Friede, La otra verdad. La independencia americana vista por los españoles (Bogotá: Carlos 
en distintos momentos en Venezuela. ${ }^{19}$ Ciertamente, después de su llegada a Quito algunos revolucionarios fueron ejecutados tanto en esta ciudad como en Ibarra y Pasto, y otros cabecillas, desterrados o confinados. No obstante, el rasgo sobresaliente del gobierno implantado por el nuevo presidente de la Audiencia de Quito fue la reconciliación que buscó con los líderes de la revolución mediante indultos, rebajas o cambios en las condenas, y el silencio y olvido de lo pasado. ${ }^{20}$ Montes comprendía, además, que la promoción de los intereses regionales era un ingrediente clave para restablecer la concordia. Por eso, se afanó en proclamar la Constitución de Cádiz en su jurisdicción, organizando prestamente las elecciones que ella ordenaba, e influyendo para que salieran favorecidos dirigentes locales - aun cuando muchos hubieran militado en la revolución-. Asimismo, Montes insistió ante las autoridades metropolitanas en el retorno a la dependencia de Quito de la gobernación de Guayaquil, que desde 1803 estaba supeditada a Lima en lo militar y que al estallar la crisis de la monarquía quedó sujetada por completo al virreinato del Perú. ${ }^{21}$ Por último, insistió también en la elevación de la Audiencia que presidía al rango de Capitanía General. ${ }^{22}$

Una buena síntesis de la política de pacificación adoptada por Montes se encuentra en los comentarios que hizo acerca de la situación del obispo José Cuero y Caicedo. A pesar de estar muy comprometido con la revolución, el presidente de la Audiencia se contentó con remitirlo tardíamente a Lima, ${ }^{23}$ ignorando la recomendación de arrestarlo y enviarlo a la Península. Consideraba Montes que, en razón de su estado, Cuero suscitaba más compasión que rigor. Además,

Valencia Editores, 1979); Daniel Gutiérrez Ardila, La Restauración en la Nueva Granada (18151819) (Bogotá: Universidad Externado de Colombia, 2016).

19. Véase José Francisco Heredia, Memorias del regente Heredia (Madrid: Editorial América, [s.f.]); Restrepo; Rafael María Baralt y Ramón Díaz, Resumen de la historia de Venezuela, t. 1 (Brujas-París: Desclée, De Brouwer, 1939); Caracciolo Parra Pérez, Historia de la primera república de Venezuela, t. 2 (Caracas: Academia Nacional de la Historia, 1959); Juan Uslar Pietri, Historia de la rebelión popular de 1814. Contribución al estudio de la historia de Venezuela (París: Ediciones Soberbia, 1954).

20. Véase Georges Lomné, "Le lis et la grenade. Mise en scène et mutation imaginaire de la souveraineté à Quito et Santafé de Bogotá (1789-1830)" (Tesis de doctorado en Historia, Université de Marne-la-Vallée, 2003) 365-375; Christiana Borchart de Moreno, "Palo y zanahoria. La política de Toribio Montes, presidente de la Audiencia de Quito", Abascal y la contra-independencia de América del Sur, eds. Scarlett O’Phelan y Georges Lomné (Lima: Instituto Francés de Estudios Andinos / Pontificia Universidad Católica del Perú, 2013) 503-534; Alexandra Rosita Sevilla Naranjo, “'Al mejor servicio del Rey'. Fidelismo, realismo y contrarrevolución en la Audiencia de Quito entre 1809 y 1822" (Tesis de doctorado en Historia de los Andes, Facultad Latinoamericana de Ciencias Sociales, 2017) 262-283.

21. María Luisa Laviana Cuetos, "Entre Quito y Lima: la disputa por Guayaquil a comienzos del siglo XIX”, José de San Martín y su tiempo, ed. Luis Navarro García (Sevilla: Universidad de Sevilla, 1999) 209-215.

22. Jaime Rodríguez, “Toribio Montes y las primeras elecciones populares en Quito”, Boletín de la Academia Nacional de la Historia XC.187 (2012): 77-104.

23. Borchart de Moreno 522. 
Hallándose aún sublevadas las ciudades de la orilla del Cauca, y siendo el Reverendo obispo natural de la principal de ellas, Cali, la noticia de su prisión que correrá inmediatamente, calculo será de una trascendencia que poniendo un detén a las medidas pacíficas con que me conduzco, alarmará más a aquellos habitantes, les hará persistir en su errado sistema y conducidos hasta el punto de la desesperación, será preciso obrar con la última energía, convirtiéndose todo en un desierto. $^{24}$

Los más fervientes realistas, que padecieron poco o mucho durante las revoluciones de Quito, rechazaron por tímida la estrategia de Montes. ${ }^{25} \mathrm{El}$ fiscal interino de la Audiencia de Quito, Víctor de Sanmiguel, se atrevió a acusarlo incluso de bonapartista, lo que produjo un gran escándalo y la destitución del abogado, que fue enviado a Pasto como teniente de gobernador. Amoscado, Sanmiguel se quejó ante las autoridades peninsulares y denunció que Montes solía pasear y comer con cabecillas de la insurgencia como el magistral Francisco Rodríguez de Soto, el provisor Antonio de Tejada o con Manuel Larrea. ${ }^{26}$

La pacificación practicada por Montes suscitó también acerbas críticas en otros puntos de la Audiencia como, por ejemplo, en Popayán, que era el inestable límite entre las comarcas revolucionarias y realistas del suroccidente del Reino. En el segundo semestre de 1813, el alférez real de la ciudad Manuel Antonio Tenorio y Carvajal se quejó así de haber sido pospuesto por Montes en el empleo de tesorero oficial real, a pesar de su activa militancia en favor de la Corona. ${ }^{27}$

El presidente de la Audiencia de Quito no estaba interesado en negar o en disimular los vínculos que estableció con revolucionarios conspicuos. Por el contrario, buscó favorecerlos ante la Corte: en marzo de 1813 respaldó la pretensión del mencionado Antonio de Tejada de obtener una de las dignidades vacantes del obispado por la colaboración que prestó en el restablecimiento del "buen orden". ${ }^{28}$ Asimismo, en el mes de diciembre propuso que se librara al también mencionado Larrea el título de marqués de San José, libre de lanzas, pues consideraba que los títulos nobiliarios unían a los americanos a la nación, como lo demostraba en su concepto el caso de Lima, que se había mantenido en inalterable fidelidad después de la crisis monárquica. ${ }^{29}$

24. Toribio Montes, "Oficio a la secretaría de Estado", Quito, 6 de marzo de 1815. AGI, Sevilla, Quito, 222.

25. Georges Lomné, “El informe de Ramón Núñez del Arco (Quito, 1813): un afán de pacificación absoluta", Abascal y la contra-independencia de América del Sur, eds. Scarlett O’Phelan y Georges Lomné (Lima: Instituto Francés de Estudios Andinos / Pontificia Universidad Católica del Perú, 2013) 535-570.

26. Las quejas de Montes acerca del fiscal interino Víctor de Sanmiguel y las denuncias de este, Quito, 7 de agosto de 1813. AGI, Sevilla, Quito, 231.

27. Antonio Astudillo, "Certificación”, Popayán, 29 de octubre de 1813. AGI, Sevilla, Quito, 276.

28. Antonio de Tejada, “Solicitud”, Quito, 22 de marzo de 1813. AGI, Sevilla, Quito, 257.

29. Toribio Montes, "Propuesta", Quito, 7 de diciembre de 1813. AGI, Sevilla, Quito, 256. 
Es en este contexto y en el marco de tan particular política de reconciliación que debe entenderse el enfrentamiento de Toribio Montes con Juan Sámano. La disputa fue perceptible en septiembre de 1813, cuando el primero escribió un duro oficio al segundo en el que le recriminaba su conducta en la expedición contra Popayán. Antes de la entrada de las tropas reales a la ciudad, Montes había asegurado a dicho cabildo que, a cambio de un sometimiento pacífico, los vecinos serían tratados "con la mayor humanidad y consideración” y sus casas, bienes y haciendas, respetados. Al mismo Sámano le había advertido que el más leve desacato lo "castigaría conforme a ordenanza", y que el "buen trato y amor" eran indispensables para "conciliar los ánimos, reunirlos y ponerlos en una tranquila paz", según demostraba la reciente experiencia de Quito. ${ }^{30}$

Sin embargo, Montes recibió numerosas quejas del vecindario de Popayán: la gente se mantenía encerrada en su casa sin atreverse a salir "porque con puñal al pecho se les arranca de sus hombros hasta la capa"; los soldados, aun así, entraban a los domicilios a robar y violentaban a los dueños para conocer, por medio de sus propios esclavos, el paradero del dinero oculto. Tampoco se aventuraban los labradores a los mercados porque se les arrebataba cuanto cargaban, ni los comerciantes a abrir las tiendas, aunque fueran de comestibles, porque la tropa arrebataba los géneros sin pagarlos. La causa de la nación española, afirmaba Montes, se había hecho odiosa de tal suerte que sus soldados eran tachados de bandidos. ${ }^{31}$

Para comienzos de 1814 (batalla de Calibío) la expedición al norte había fracasado por completo. Sámano tuvo que retirarse de Popayán con su ejército el 15 de enero, guarneciéndose en Pasto "en el mayor desorden", sin cuidarse de retirar las matrices de la casa de moneda ni de embarcar consigo los veinte cajones de barajas y la imprenta nueva que había en la capital de la gobernación. Su huida se había producido en desmedro de la artillería y las municiones, así como de un número considerable de fusiles. Las causas del descalabro eran clarísimas para Montes, quien las expuso así al capitán general del Nuevo Reino:

A esto ha dado lugar la falta de política del expresado Sámano, el desprecio con que ha mirado a sus oficiales, lo cual ocasionó que uno de ellos se pasase a los enemigos, el no procurar contener su tropa en subordinación y disciplina, y el no haber dado oído a las quejas de aquellos naturales, que hostigados y exasperados, procuraron levantarse a favor del presidente de Cundinamarca Don Antonio Nariño, faltando Sámano en todo a mis órdenes y a la instrucción que le di por escrito antes de su salida de esta capital, y que en agosto y sucesivamente le previne su traslado a la ciudad de La Plata con la mayor parte de sus fuerzas, lo cual no obedeció, sin embargo que envié de aquí un coronel para que se encargase del mando de Popayán y su provincia, pero por

30. Toribio Montes, “Carta a Juan Sámano”, Quito, 21 de septiembre de 1813. AGN, Bogotá, Sección Archivo Anexo, Historia, t. 15, ff. 139-141.

31. Toribio Montes, “Carta a Juan Sámano”, Quito, 21 de septiembre de 1813.AGN, Bogotá, Sección Archivo Anexo, Historia, t. 15, ff. 139-141. 
su tenacidad en no dejarlo y pretextar que solo dependía de Vuestra Excelencia ha causado y ha sido el origen de tan grave daño a la Nación y a estos territorios inmediatos. ${ }^{32}$

Montes concluía su oficio indicando que las tropas supérstites habían sido confiadas a Melchor de Aymerich y que Sámano, exonerado del mando, sería destinado a Panamá, donde aguardaría "la resolución del Supremo Consejo de Regencia", al cual había "dado parte circunstanciadamente de las faltas cometidas, de que sin duda es responsable a la nación". ${ }^{33}$

Con el retorno de Fernando VII a la Península varió radicalmente la trama del poder en Quito. Entonces comenzaron a ganar fuerza las censuras a propósito de la manera en que Montes había pacificado el territorio de la Audiencia. Estas se manifestaban en dos sentidos complementarios: por una parte, mediante la denuncia del favorecimiento dado a los "criminales"; por otra, a través de las quejas por la injusta relegación de los buenos vasallos. En 1815, por ejemplo, Montes debió explicar a las autoridades de la monarquía las razones por las cuales se abstuvo de remitir a España al marqués de Selva Alegre, a pesar de su probada infidencia, de su participación en los gobiernos revolucionarios quiteños de 1809 y 1810 y de su adhesión “a la independencia de Santa Fe”. Según indicó entonces Montes, se contentó con confinarlo en la ciudad de Loja no solo por las enfermedades que aquejaban al reo, sino también por el clamor general de las primeras familias. Al cabo de dos años, el antiguo presidente de la Junta de Quito se fugó, pero Montes, indulgente, le permitió residir en su hacienda de Chillo. ${ }^{34}$ También en 1815 el cabildo de Cuenca acusó a Montes de gobernar en favor de los facciosos y de perjudicar a los verdaderos realistas mediante la transformación maliciosa de sus servicios en deméritos. Tal cosa había ocurrido, por ejemplo, con el gobernador de la provincia Melchor de Aymerich (que como se recordará servía al frente de las tropas en Pasto), a quien el presidente de la Audiencia impidió pasar a Quito a restablecer su salud por considerarlo inconveniente para la tranquilidad pública. Aymerich, iracundo, le recordó a Montes que era gobernador por el rey y no por "las alevosas cortes, que creaban seres políticos a medida de sus ideas". ${ }^{35}$ Con todo, debió dirigirse a Cuenca por caminos

32. Toribio Montes, "Carta a Francisco de Montalvo", Quito, 7 de abril de 1814. AGN, Bogotá, Sección Archivo Anexo, Historia, t. 17, ff. 72-73.

33. Toribio Montes, "Carta a Francisco de Montalvo", Quito, 7 de abril de 1814. AGN, Bogotá, Sección Archivo Anexo, Historia, t. 17, ff. 72-73.

34. "Minuta del Consejo de Indias", Madrid, 7 de junio de 1816. AGI, Sevilla, Quito, 219.

35. "El Cabildo de Cuenca informa sobre los agravios hechos a su gobernador Aymerich", Cuenca, 11 de marzo de 1815. AGI, Sevilla, Quito, 276; “El gobernador de Cuenca da parte al Sr. Capitán General del desaire con que se ha retirado a su gobierno y de las contestaciones que mediaron entre él y el comandante de Quito D. Toribio de Montes, de resultas de la dimisión que hizo del mando al Ejército que operaba desde Popayán". AGN, Bogotá, Sección Archivo Anexo, Gobierno, t. 26, ff. 579-588. 
extraviados, siguiendo el ejemplo de Antonio Nariño, meses atrás, cuando se le conducía preso a España vía Lima. ${ }^{36}$

\section{De Quito a Santa Marta}

Cuando se enteró en 1816 de la rendición de Cartagena, luego de un costoso bloqueo del Ejército Pacificador, Toribio Montes confió a Sámano el mando de una nueva expedición contra Popayán, no obstante sus pasados sinsabores. Los 900 hombres de tropa salieron de Pasto el 14 de mayo y se instalaron en la Cuchilla del Tambo (a seis leguas de Popayán) donde vencieron a los insurgentes. ${ }^{37} \mathrm{La}$ batalla cambió el destino del malhadado militar tanto como el nuevo contexto, inaugurado por la restauración de Fernando VII y la coincidencia de miras con Pablo Morillo y otros partidarios de la línea dura de la pacificación. ${ }^{38}$

Consciente del cambio de rumbo de la monarquía, Montes refirió amargamente en carta al virrey Francisco de Montalvo lo desventajosa que resultaba en aquellos momentos una mengua de su autoridad:

y después, finalmente, que la experiencia me ha hecho conocer a fondo el carácter de los habitantes, que puedo distinguirlos y destinarlos con acierto, veo con dolor un trastorno en el orden político, nada conforme a las prudentes reglas que deben adoptarse para el restablecimiento de la tranquilidad pública, la subordinación de los vasallos y el sistema antiguo de gobierno. ${ }^{39}$

El viraje, pensaba Montes, no solo era catastrófico para la integridad del imperio. Había tenido, además, repercusiones lamentables en la estructura jerárquica y en el principio mismo de la autoridad:

Sin comunicárseme disposición alguna deVuestra Excelencia, sin contar conmigo para instruirse a fondo de las cosas por el conocimiento que tengo de ellas, y últimamente sin usar de los medios de atención y urbanidad de que no debieron prescindir por mi carácter y empleo, se han expedido órdenes a los administradores y tesoreros de los ramos reales de Pasto, su provincia y Barbacoas para que suspendan toda contribución que de los caudales de su cargo exija esta comandancia general en lo sucesivo para el socorro del ejército y a los gobernadores de ellas, para que con infidencia de esta superioridad se entiendan en todos los asuntos con el gobierno de Popayán. Hasta la fecha no tengo una razón oficial que me instruya del sujeto en quien legítimamente haya recaído el mando de la indicada provincia por la separación que ha hecho de ella

36. Cevallos 192-193.

37. Toribio Montes, "Carta a Francisco de Montalvo”, Quito, 22 de julio de 1816. AGN, Bogotá, Sección Archivo Anexo, Historia, t. 20, ff. 692-693.

38. Sobre la línea dura y la línea blanda de la pacificación, véase Friede; Stephen K. Stoan, Pablo Morillo and Venezuela, 1815-1820 (Columbus: Ohio State University Press, 1974); Lomné, "Le lis et la grenade" 365-375 y 383-415.

39. Toribio Montes, "Carta a Francisco de Montalvo", Quito, 6 de octubre de 1816. AGN, Bogotá, Sección Archivo Anexo, Historia, t. 21, f. 400. 
el brigadier D. Juan Sámano, dirigiéndose a Santa Fe, a donde ha sido llamado por el general D. Pablo Morillo sin anuencia mía, después que servía bajo mis órdenes.

Del mismo modo, ignoro las miras que tenga el jefe del segundo batallón de Numancia que debía estar a mi disposición, según me lo previno el expresado general Morillo, porque hasta la fecha nada me dice, sin embargo de hallarse en Popayán, cuyo vecindario clama por la opresión y extorsiones que sufre, lastimando demasiado mi sensibilidad que repugna tales procedimientos, como diametralmente opuestos a las piadosas intenciones del soberano. ${ }^{40}$

De hecho, Sámano, no contento con desconocer a su superior natural, arrastró consigo tropa y oficiales de Quito para formar con ellos un batallón en Santa Fe. Como la fuerza se componía de cuencanos, guayaquileños y limeños que veían con malos ojos un proyecto que los alejaba aún más de sus hogares, el resultado forzoso fue la deserción y la pérdida de parte del armamento. ${ }^{41}$

De acuerdo con los oficios de Montes, la intromisión de los oficiales del Ejército Pacificador no solo perturbó a la Real Hacienda, al gobierno y a la estructura militar. Aun las más sencillas disposiciones del presidente de la Audiencia de Quito se veían contrariadas por los mandos del Ejército de Costa Firme. A comienzos de marzo de 1817, Montes se quejó una vez más ante el virrey Montalvo porque habían sido ignoradas las órdenes que dio de remitir a Guayaquil y Lima, amenazadas por la incursión de los bonaerenses en Chile, las armas empleadas en la pacificación de la provincia de Popayán, así como las tomadas a los revolucionarios en la Cuchilla del Tambo. En efecto, por disposición del coronel Francisco Warleta, no pasaron de Pasto, cuyos habitantes se servían de ellas "cada uno en particular". ${ }^{42}$

Muy pronto se confirmó el cambio político que la desobediencia de Sámano y su entendimiento con Morillo dejaban presagiar. El 5 de julio de 1816 las autoridades de la monarquía habían comunicado por la vía reservada al virrey del Perú la "urgente necesidad" de separar a Montes de la presidencia de Quito y el nombramiento de Juan Ramírez Pizarro en su remplazo. ${ }^{43}$ Cuando conoció la noticia, así como la elevación de Juan Sámano a la comandancia de la Tercera División y a la gobernación de la provincia de Santa Fe, Montes optó por escribir cartas a su antiguo subordinado en un tono muy diferente del empleado en 1813 y 1814 , cuando lo reprendía con dureza por su desatinada pacificación de Popayán. Por fortuna, algunas de esas cartas se conservan en diversos fondos del Archivo General de la Nación, por cuanto luego de la batalla de Boyacá (7 de agosto de 1819) el

40. Toribio Montes, "Carta a Francisco de Montalvo”, Quito, 6 de octubre de 1816. AGN, Bogotá, Sección Archivo Anexo, Historia, t. 21, f. 400.

41. Toribio Montes, "Carta a Francisco de Montalvo", Quito, 6 de octubre de 1816. AGN, Bogotá, Sección Archivo Anexo, Guerra y Marina, t. 153, f. 513.

42. Toribio Montes, "Carta a Francisco de Montalvo", Quito, 6 de marzo y 21 de abril de 1817. AGN, Bogotá, Sección Archivo Anexo, Guerra y Marina, t. 153, f. 509-511.

43. "Oficio reservado de la Secretaría de Guerra al virrey del Perú", Madrid, 5 de julio de 1816. AGN, Bogotá, Sección Archivo Anexo, Guerra y Marina, t. 140, f. 953. 
virrey, acompañado de las demás autoridades superiores del Nuevo Reino, salió despavorido abandonando incluso su correspondencia privada.

El 6 de julio de 1817 Montes lamentó la muerte del teniente coronel Julián Bayer a manos de los patriotas del Casanare, achacándola al hecho de que la fuerza que comandaba se componía de payaneses y caleños. Afirmó entonces que no convenía "admitir en el servicio ni valerse de los que han sido contrarios a la justa causa", mas no por ello se privó de agregar a continuación su fe política con respecto a la pacificación: "Yo soy de la opinión que si a los vecinos de estos países no se les trata con dulzura, y como a vasallos del rey de España, siempre saltarán chispas de los descontentos y tardará en pacificarse el país y [en] disfrutar de la tranquilidad y sosiego de Quito desde nuestra entrada". Esperaba ya en esa fecha a su sucesor en la presidencia de la Audiencia y confiaba poder emprender su viaje de retorno a la Península por "Guayaquil o Panamá", prometiendo velar por el adelantamiento de Sámano en la Corte. ${ }^{44}$

El 6 de agosto de 1817, es decir, algunos días después de la llegada a Quito del nuevo presidente de la Audiencia, Juan Ramírez Pizarro, ${ }^{45}$ Montes continuó cortejando a su antiguo subordinado, felicitándolo por la cruz de San Hermenegildo con que había sido condecorado y por su ascenso a mariscal de campo, mientras trataba de convencerlo de que tal promoción se debía a sus cuidados y no a los de Morillo. ${ }^{46}$ En enero de 1818 se alegró en una nueva misiva por la elevación de Sámano al virreinato, comentó que una "terrible hinchazón en los pies" lo tenía postrado desde hacía cinco meses y anunció que en cuarenta días esperaba estar restablecido para emprender su camino hacia la España por tierra, cambio de rumbo debido al hecho de que los mares de Guayaquil se hallaban infestados de piratas, "tanto, que siete buques han acometido a la isla de Tumaco, han pegado fuego a la población y llevádose cuanto han podido". ${ }^{47}$ Sámano se tragó sus opiniones y correspondió a las cortesías de su enemigo anunciándole que en Pasto había órdenes de tener caballerías listas a su disposición, y prometiéndose que a pesar de la distancia a que se hallaba Quito habría de llegar allí “gordo y fuerte”. Eso sí, optó por tachar en el borrador de la carta el pasaje en que lo invitaba a pasar por Santa Fe para tener la "fortuna" de verlo. ${ }^{48}$

La enfermedad de Montes quizás era una artimaña para permanecer en Quito e impedir con su presencia que la obra política que tantos esfuerzos le había costado fuera abatida en un santiamén, y que quienes habían sido sus apoyos pagaran los

44. Toribio Montes, “Carta a Juan Sámano”, Quito, 6 de julio de 1817. AGN, Bogotá, Sección Archivo Anexo, Particulares, t. 9, ff. 12-13.

45. Cevallos 217.

46. Toribio Montes, “Carta a Juan Sámano”, Quito, 6 de agosto de 1817. AGN, Bogotá, Sección Archivo Anexo, Particulares, t. 9, ff. 11 y 19.

47. Toribio Montes, "Carta a Juan Sámano”, Quito, 6 de enero de 1818. AGN, Bogotá, Sección Archivo Anexo, Particulares, t. 9, f. 14.

48. Juan Sámano, "Carta a Toribio Montes”, Santa Fe, 6 de febrero de 1818. AGN, Bogotá, Sección Archivo Anexo, Particulares, t. 9, f. 15. 
platos rotos. En todo caso, su estadía sin mando no fue muy grata, según informó a Sámano el doctor Miguel Araújo desde Otavalo a finales de febrero de 1818:

Nada ha entorpecido las operaciones del jefe su permanencia en Quito, pues casi no ha habido día en que no haya recibido golpes en su cara. Cabildo repuesto, D. Andrés Salvador restablecido en la procuración general, todas sus criaturas abatidas; realistas acariciados o premiados; Soto, Valdivieso, Mateus, Selvalegre caminando a España; Reales órdenes puestas en ejecución, etc. ${ }^{49}$

Montes partió finalmente de la capital de la Audiencia en marzo de 1818, mas se detuvo durante un mes en la quinta de Añaquito. Allí se dedicó a escribir sin pausa, según denunció el doctor Joaquín Miguel de Araujo, y a formar, de acuerdo con las malas lenguas, sumarias con fechas anticipadas, ${ }^{50}$ es decir, a confeccionar procesos judiciales que sirvieran de resguardo a antiguos revolucionarios. Cuando se puso nuevamente en tránsito hacia el norte continuó sembrando cizaña por todo el camino, de acuerdo con el mismo corresponsal del virrey, "no habiéndose contentado con dejar en este país males insanables, que no podremos llorarlos bastantemente" ${ }^{51}$ Otro informante de Sámano, el doctor León Pereda de Saravia, coincidía en la especie. Indicaba que Montes había circulado "célebres oficios y proclamas" a cuanto fraile y empleado había en el distrito, con el objeto estudiado de infundir odio y aversión por la autoridad de su sucesor al tiempo que buscaba indemnizarse por los "inmensos errores y desaciertos" cometidos durante su mandato. ${ }^{52}$ Alguno de los amigos de Sámano en Quito tuvo el cuidado de remitir uno de aquellos papeles confeccionados por Montes antes de su partida que nuevamente citaré in extenso, porque expresa sin ambigüedades su postura frente a la pacificación y su oposición a la variación en Quito de políticas de probada eficacia:

Encargado de pacificar los pueblos conmovidos, yo tomé sobre mí con la presidencia el empeño de su arreglo en las delicadas circunstancias de haber prendido el fuego de la revolución por todas partes. Jamás perdí de vista que el suceso de tan ardua empresa estaba indicado en el orden mismo de la naturaleza, y en las repetidas providencias, no solo de la Regencia del Reino, sino del mismo soberano. Conformado mi sistema de gobierno a las benéficas miras e intenciones del rey, yo he pacificado a Quito: he restituido esta capital y sus provincias a su legítimo soberano: he mantenido la tranquilidad interior, he dirigido y costeado tres expediciones sobre la provincia de Popayán, y he visto con placer que cuando la desolación y la sangre no podían extinguir en otros reinos la sedición y el trastorno, una conducta de moderación me proporcionaba más

49. Joaquín Miguel de Araujo, “Carta a Juan Sámano”, Otavalo, 22 de febrero de 1818.AGN, Bogotá, Sección Archivo Anexo, Particulares, t. 9, ff. 549 y 551.

50. Joaquín Miguel de Araujo, "Carta a Juan Sámano", Quito, 6 de abril de 1818. AGN, Bogotá, Sección Archivo Anexo, Particulares, t. 9, ff. 677 y 679.

51. Joaquín Miguel de Araujo, "Carta a Juan Sámano”, Quito, 21 de junio de 1818. AGN, Bogotá, Sección Archivo Anexo, Historia, t. 24, f. 51.

52. León Pereda de Saravia, "Carta a Juan Sámano”, Quito, 6 de julio de 1818. AGN, Bogotá, Sección Archivo Anexo, Historia, t. 24, ff. 100-101. 
gloriosos triunfos que los que me habrían dado la espada y los suplicios. Usé de éstos dentro de los términos de la más estrecha necesidad: economicé la sangre, busqué recursos para el sostén de los ejércitos en la opulencia de los revoltosos y obedeciendo los indultos del rey, acomodados a los sentimientos de mi corazón, he tenido la dulce satisfacción de consolidar la quietud y seguridad pública, sin sembrar de cadáveres los campos, sin amontonar los cadalsos, sin destruir las campiñas y sin enlutar los pueblos. ${ }^{53}$

Desde Pasto, Tomás de Santa Cruz felicitó a Sámano por su elevación al rango de virrey y aprovechó para pedirle que lo recordara a él y a su familia, quizá con un puesto en la casa de moneda de Popayán donde, según afirmó, había empleada gente carente de méritos, con lo que se refería a sacrificios probados por la causa del rey. Santa Cruz también dio parte a Sámano de la llegada de Montes a Ipiales. Calculaba que se presentaría en Pasto una semana más tarde y como tendría que pasar por Yacuanquer, el corresponsal afirmó que se abstendría de temperar allí con su familia para no honrarlo ni ofrecerle "hospicio": "no tengo por qué hacerlo", afirmó lapidario. ${ }^{54}$

Montes arribó a Popayán el 5 de mayo y permaneció en la ciudad por 21 días. Lo recibieron vecinos principales que le debían "distinguidos favores", como José María Mosquera Figueroa. Este refirió la llegada del mandatario a su compadre Miguel Tacón, antiguo (y polémico) gobernador de la provincia, en términos que indican que la pérdida de poder en las precisas circunstancias de la pacificación morillista era sentida por muchos como una suerte más que como una calamidad: "Dios ha querido premiarle su bondad con haberlo libertado de que lo hicieran virrey de Santa Fe, cuyos moradores y las relaciones tan íntimas con el ejército expedicionario de Caracas le habrían causado grandes incomodidades, y lo pasará mil veces mejor en España, donde no carece de amigos y buenas relaciones". Mosquera aprovechó el paso de Montes por Popayán para solicitarle un nuevo favor. Sabiendo que se disponía a viajar a España, le rogó que intercediera por su cuñado Antonio Arboleda Arrachea, quien había sido deportado a la Península por sus vínculos con la revolución. ${ }^{55}$

El 3 de junio Montes se encontraba en la ciudad de La Plata y desde allí escribió nuevamente a Sámano para denunciar que todos los pueblos que había recorrido desde Popayán se hallaban sin vecinos y que los tambos del tránsito estaban desiertos y sin cubierta, de modo que, si no se destinaba quién los cuidara, desaparecerían en breve. Aludió también a las quejas de los vecinos de Popayán y del valle

53. Toribio Montes, "Rasgo sobre su gobierno remitido al cabildo eclesiástico de Quito desde Popayán”, el 16 de mayo de 1818. AGN, Bogotá, Sección Archivo Anexo, Historia, t. 24, ff. 55-56.

54. Tomás de Santa Cruz, "Carta a Toribio Montes", Pasto, 13 de abril y 12 de mayo de 1818. AGN, Bogotá, Sección Archivo Anexo, Particulares, t. 9, ff. 691 y 694.

55. “José María Mosquera y Figueroa a Miguel Tacón, a Joaquín Mosquera Arboleda y a Antonio Arboleda (Popayán, 20 de mayo y 5 de septiembre de 1818 y 5 de abril de 1819)", Epistolario de José María Mosquera y Figueroa, ed. Manuel Pareja Ortiz (Chía: Universidad de la Sabana, 2018) 90-92, 107-108 y 119-125. 
del Cauca por lo oneroso que les resultaba mantener un batallón, ya que, además de la ración, debían costear uniformes fabricados "con el mayor lujo". Ceremoniosamente lamentó no poder pasar por Santa Fe, pues planeaba dirigirse a Neiva y embarcarse por el Magdalena hasta el Caribe con el fin de aprovechar el verano para efectuar la travesía del Atlántico. ${ }^{56}$ Efectivamente, el 19 de junio Montes se hallaba en Honda, ciudad desde la que escribió una vez más al virrey anunciándole su partida rumbo a Mompox para el día 23 y agradeciéndole por las gacetas que le había remitido. ${ }^{57}$ Se embarcó, en realidad, un día más tarde, según puntual aviso que recibió Sámano de un informante. ${ }^{58}$ El retraso en la reanudación del viaje se debió en parte a que los champanes disponibles se emplearon por orden superior en la remisión de presidiarios y en el transporte de los oficiales y tropa encargados de custodiarlos. ${ }^{59}$ Se insultaba su alta dignidad sometiéndola a tales dilaciones y dando prioridad al trajín de reos.

El 1 de julio de 1818 termina la correspondencia de Montes con Sámano. Ese día el antiguo presidente de Quito le escribió desde Mompox, adonde había llegado dos días antes. Estaba a la espera de "dos buquecitos procedentes de Santa Marta" para dirigirse a dicha ciudad por el caño Clarín, ya que, por falta de naves, no podría embarcarse en Cartagena con destino a Jamaica u otro punto de tránsito en el Caribe. Antes de abandonar el puerto fluvial tuvo a bien interceder ante el virrey por Nicolás del Campo Larraondo, un payanés comprometido con la revolución. Hasta el final de sus días en el virreinato, Montes abogó con coherencia por una restauración clemente, que más que un lujo era, en su sentir, una necesidad política:

Este sujeto, aunque al principio estuvo mezclado en [los trastornos de] Cali, de donde es vecino y cuñado del Presidente Caicedo, no ha vuelto a tomar parte [en ellos] desde la primera entrada de usted en Popayán, y por consiguiente es acreedor al real indulto. En la última entrada se retiró a Quito, donde ha vivido con su hermana sin dar la más leve nota de su persona, y últimamente ha llegado allí fiado en aquella gracia, pero como no faltan émulos, tratan de perseguirlo personas que aseguran tienen toda la confianza de usted y por lo mismo prevendrá usted lo conveniente a Popayán y Cali para que no se le moleste, pues este es el seguro medio de que se olvide todo lo pasado. $^{60}$

56. Toribio Montes, "Carta a Juan Sámano”, La Plata, 3 de junio de 1818. AGN, Bogotá, Sección Archivo Anexo, Particulares, t. 10, ff. 101-102.

57. Toribio Montes, "Carta a Juan Sámano”, Honda, 22 de junio de 1818. AGN, Bogotá, Sección Archivo Anexo, Particulares, t. 11, f. 502.

58. Pablo Aguiar, "Carta a Sámano”, Honda, 25 de junio de 1818. AGN, Bogotá, Sección Archivo Anexo, Guerra y Marina, t. 160, f. 45.

59. Juan Sámano, "Carta a Juan Ramírez", Santa Fe, 21 de julio de 1818. AGN, Bogotá, Sección Archivo Anexo, Guerra y Marina, t. 160, f. 198.

60. Toribio Montes, "Carta a Juan Sámano”, Mompox, 1 de julio de 1818. AGN, Bogotá, Sección Archivo Anexo, Particulares, t. 9, f. 17. 
Montes pasó casi todo el mes de julio en Mompox. El virrey Sámano escribió el día 21 al presidente de la Audiencia de Quito, Juan Ramírez, una carta privada en la que indicaba que a pesar de transitar "por paraje próximo" el intrigante viajero había evitado tocar en Santa Fe. Había, sí, anunciado su itinerario y su intención de pasar a Santa Marta, rogando que se ajustase su sueldo hasta el día de su embarque. Sámano, visiblemente inquieto por la deambulación del teniente general, remitió copia de una carta del obispo de Popayán en la cual, según indicó, se proveía una explicación de tan misteriosa parsimonia (por desgracia, esta no se encuentra en los archivos) ${ }^{61}$ A vuelta de correo, Ramírez reconoció que nada de cuanto hiciera o dijera Montes le era "peregrino". Le había guardado las "mayores consideraciones", a pesar de los abusos, pero no habiendo duda de que el depuesto presidente aprestaba "su artillería para batir hombres de bien", estaba decidido a replicarle con una "metralla" muy dañina, respaldada por documentos auténticos. No se explicaba por qué en su perezoso tránsito se le habían franqueado a Montes "algunas piezas o certificados" que, aunque aquejados por una "conocida ligereza de parte", podían despistar al "ignorante". Recomendaba, por ello, hacer las indagaciones pertinentes "para no descuidarse ni desentenderse a la justa reciprocidad". ${ }^{62}$

Queda claro, pues, que para el virrey del Nuevo Reino y para el presidente de la Audiencia de Quito el lento tránsito de Montes se debía a una estrategia maliciosa encaminada a desprestigiar tanto la política de pacificación adoptada desde 1816 como a sus principales ejecutores. La detención del viejo teniente general en las diversas villas y ciudades, pensaban ambos mandatarios, tenía como propósito preciso la acumulación de documentos probatorios, cuya suma debía producir nocivos efectos en la Corte.

Luego de su estancia en Mompox, Montes se dirigió a Santa Marta en donde fue nuevamente agasajado por miembros de una de las más importantes familias de Popayán. El joven Joaquín Mosquera Arboleda había tenido que emigrar a Jamaica por sus compromisos con la revolución y regresado recientemente al Nuevo Reino en compañía de su hermano Tomás Cipriano. Ambos lo acompañaron en los paseos vespertinos y quedaron prendados de su "bellísimo carácter y amabilidad". ${ }^{6}$

Montes se embarcó finalmente rumbo a Jamaica con la idea de llegar a España a través de Inglaterra. Desde La Habana, Sámano recibió carta de un corresponsal anónimo que hizo el viaje con el vigilado exmandatario en una fragata de guerra inglesa. En lugar de continuar rumbo a Europa, ambos pasaron a Cuba, isla a la que

61. Juan Sámano, "Carta a Juan Ramírez”, Santa Fe, 21 de julio de 1818. AGN, Bogotá, Sección Archivo Anexo, Guerra y Marina, t. 160, f. 198.

62. Juan Ramírez, "Carta a Juan Sámano”, Quito, 21 de agosto de 1818. AGN, Bogotá, Sección Archivo Anexo, Guerra y Marina, t. 160, ff. 197 y 198 bis.

63. "José María Mosquera y Figueroa a su hijo Joaquín y a Toribio Montes (Popayán, 5 de septiembre y 20 de octubre de 1818)", Epistolario de José María Mosquera y Figueroa, ed. Manuel Pareja Ortiz (Chía: Universidad de la Sabana, 2018) 107-110; "Joaquín Mosquera a Santiago Arroyo (Santa Marta, 30 de julio de 1818)", Epistolario de Joaquín Mosquera (1845-1874), ed. Marcela Revollo Rueda (Chía: Universidad de la Sabana, 2018) 59-61. 
llegaron el 1 de septiembre de 1818. Aparentemente, la intención de Montes era "detenerse hasta el buen tiempo", cuando reanudaría su viaje con el antiguo virrey del Nuevo Reino, Francisco de Montalvo, quien pretendía ser oído en la corte "en algunas cosas". ${ }^{64} \mathrm{Ni}$ con el alejamiento de Montes del Nuevo Reino cesaron las alarmas de los morillistas. La reunión del antiguo presidente de la Audiencia de Quito con el exvirrey acrecentaba de hecho las sospechas por cuanto ambos habían contrariado con empecinamiento las políticas represivas.

\section{4. ¿Un cuento filosófico?}

El siglo XVIII despreciaba el género novelístico como frívolo e inverosímil y valoraba, en cambio, el cuento filosófico que, de acuerdo con Voltaire, divertía al lector mientras le presentaba por caminos extraviados ejemplos virtuosos y verdades morales. En lugar de complejidades espirituales o descripciones realistas del mundo, se trataba de fábulas esquemáticas, pero simbólicamente poderosas, cuyos personajes, casi alegóricos, solían embarcarse en viajes complejos que les permitían acceder a la razón y a la lucidez. ${ }^{65}$

Vista desde hoy, la perezosa trayectoria de Toribio Montes a través del Nuevo Reino entre marzo y agosto de 1818 parece un cuento filosófico. Un hombre viejo y poderoso pierde su influencia en el gobierno y ve cómo su sucesor implementa políticas enteramente opuestas a las que caracterizaron su labor durante un lustro. No obstante, en lugar de iniciar un viaje veloz que lo lleve de vuelta a su patria, opta por dilatar durante semanas su partida y a continuación emprende una peregrinación lenta, sembrada de etapas largas, en países regentados por sus enemigos. Esta decisión suscita una suerte de paranoia entre los dirigentes civiles y militares del día, que analizan su presencia como un reproche escandaloso al ejercicio de su autoridad y como una censura que entorpece sus acciones.

¿Acaso su avanzada edad obligó a Montes a detenerse frecuentemente para recuperarse de los malos caminos y de las largas jornadas a caballo? En los numerosos informes que acerca de su tránsito escribieron por vía epistolar los aterrados jefes realistas, nada indica dolencias persistentes o enfermedades graves. Tampoco mencionó el viejo teniente general quebrantos de salud, achaques o fatigas en sus cartas cortesanas al virrey. ¿Por qué entonces tardó tanto? ¿Por qué, en vez de desaparecer de una buena vez, de disimular la mengua de su prestigio y de silenciar su derrota,

64. “Carta anónima a Juan Sámano”, La Habana, 20 de septiembre de 1818. AGN, Bogotá, Sección Archivo Anexo, Particulares, t. 11, f. 616.

65. Haydn Mason, "Voltaire et le conte philosophique", Revue Internationale de Philosophie 48.187 (1994): 55-64. Los principales rasgos de esta definición pueden aplicarse también a la obra de Diderot, quien buscaba a través del género en cuestión "presentar un drama moral que le permitiera desarrollar sus preocupaciones filosóficas" y "hacer una propaganda socialmente ambiciosa de una tesis general" sin que sus propósitos se vieran entorpecidos por el realismo, que solo consideraba pertinente "en función de los personajes y de sus ideas". Robert Niklaus, "Diderot et le conte philosophique", Cahiers de l'Association Internationale des Études Françaises 13 (1961): 299-315. 
la exhibió como un triunfo en seis provincias del Nuevo Reino? No solo nuestro presente sugiere leer el viaje de Montes a la manera de un cuento filosófico. Sus mismos contemporáneos lo analizaron como la defensa intempestiva de otra pacificación, clemente y contemporizadora, en el contexto de una restauración frecuentemente feroz, intransigente y vengativa.

Esta lectura estaba sustentada, además, por la perturbadora pareja que el depuesto presidente de la Audiencia de Quito componía con otro anciano, experimentado militar como él y como él peninsular: Juan Sámano. Uno y otro coincidieron en la defensa de España en Quito hasta enemistarse a causa de los excesos cometidos por las tropas realistas en Ibarra y Popayán. Sámano nunca le perdonó a Montes las duras reprensiones con que lo humilló y por eso en 1816 se apresuró a desconocer su mando desfalleciente, protegido por los altos mandos del ejército pacificador. Antes de partir hacia Santa Fe se cuidó, además, de alentar el desacato general de las autoridades de la gobernación de Popayán y de llevarse tropas y armas que se echaban de menos en Quito y Guayaquil.

El encumbramiento de Montes se produjo durante la crisis de la monarquía, en medio de las revoluciones americanas; Sámano llegó a la cúspide de su carrera de la mano del restablecido Fernando VII, al cabo de las guerras napoleónicas y en el contexto del triunfo indisputable de la contrarrevolución en el Nuevo Reino. La despedida americana de Montes en 1818 fue lenta y estuvo cargada de ironía. Un año después, Sámano abandonó Santa Fe a toda carrera, aterrado por la derrota de la Tercera División en el campo de Boyacá (7 de agosto de 1819). Iba disfrazado de campesino sabanero y no recuperó el resuello hasta llegar a Cartagena. Un aura de ridículo y comedia tiñó su retirada y profanó sin remedio su alta dignidad.

La polémica por la forma más conveniente de pacificación se resolvía así, tardíamente, a favor de Montes. Quizás el depuesto presidente de la Audiencia de Quito imaginaba el desenlace y por eso marchaba paso entre paso, como si abrigara la secreta esperanza de presenciar el desplome del viejo edificio monárquico. Aturdidos por el nítido contraste político que encarnaban los dos viejos militares peninsulares, algunos llegarían a preguntarse con el tiempo "si la suerte del virreinato hubiera sido otra, si Morillo, lejos de fijarse para que lo rigiera después de él en un hombre como Sámano, el menos a propósito para gobernar, se hubiese fijado en el entendido y discreto Montes". ${ }^{66}$ Leían el pasado como un cuento filosófico.

\section{Fuentes}

\section{Manuscritas}

Archivo General de Indias, Sevilla (AGI)

Quito

Archivo General de la Nación, Bogotá (AGN)

66. Cevallos 211. 
Sección Archivo Anexo

Guerra y Marina

Gobierno

Historia

Particulares

Archivo General de Puerto Rico, San Juan (AGPR)

Fondo Capitanía General

\section{Impresas}

Heredia, José Francisco. Memorias del regente Heredia. Madrid: Editorial América, [s.f.]. Melo, Jorge Orlando. Ed. Escritos económicos. Antonio de Narváez, José Ignacio de Pombo. Bogotá: Banco de la República, 2010.

Pareja Ortiz, Manuel. Ed. Epistolario de José María Mosquera y Figueroa. Chía: Universidad de la Sabana, 2018.

Revollo Rueda, Marcela. Ed. Epistolario de Joaquín Mosquera (1845-1874). Chía: Universidad de la Sabana, 2018.

\section{Bibliografía}

Amaya, José Antonio y Iván Felipe Suárez. Ojos en el cielo, pies en la Tierra. Mapas y libros en la vida del Sabio Caldas Mapas, libros e instrumentos en la vida del Sabio Caldas. Bogotá: Museo Nacional de Colombia, 2018.

Baralt, Rafael María y Ramón Díaz. Resumen de la historia de Venezuela. Tomo 1. Brujas-París: Desclée, De Brouwer, 1939.

Borchart de Moreno, Christiana, "Palo y zanahoria. La política de Toribio Montes, presidente de la Audiencia de Quito", Abascal y la contraindependencia de América del Sur. Eds. Scarlett O’Phelan y Georges Lomné. Lima: Instituto Francés de Estudios Andinos / Pontificia Universidad Católica del Perú, 2013.

Cevallos, Pedro Fermín. Resumen de la historia del Ecuador desde su origen hasta 1845. Tomo 3. Guayaquil: Imprenta de la Nación, 1886.

Díaz Díaz, Oswaldo. La Reconquista española. 2 volúmenes. Bogotá: Academia Colombiana de Historia, 1964.

Friede, Juan. La otra verdad. La independencia americana vista por los españoles. Bogotá: Carlos Valencia Editores, 1979.

Gutiérrez Ardila, Daniel. La Restauración en la Nueva Granada (1815-1819). Bogotá: Universidad Externado de Colombia, 2016.

Laviana Cuetos, María Luisa. "Entre Quito y Lima: la disputa por Guayaquil a comienzos del siglo XIX". José de San Martín y su tiempo. Ed. Luis Navarro García. Sevilla: Universidad de Sevilla, 1999.

Lomné, Georges. “El informe de Ramón Núñez del Arco (Quito, 1813): un afán de pacificación absoluta". Abascal y la contra-independencia de América del 
Sur. Eds. Scarlett O’Phelan y Georges Lomné. Lima: Instituto Francés de Estudios Andinos / Pontificia Universidad Católica del Perú, 2013. . "Le lis et la grenade. Mise en scène et mutation imaginaire de la souveraineté à Quito et Santafé de Bogotá (1789-1830)". Tesis de doctorado en Historia, Université de Marne-la-Vallée, 2003.

McFarlane, Anthony. Colombia antes de la independencia. Economía, sociedad y política bajo el dominio borbón. Bogotá: Banco de la República / El Áncora Editores, 1997.

Márquez, Miguel B. "Sobre los comienzos del periodismo en Puerto Rico". Ámbitos. Revista Andaluza de Comunicación 3-4 (1999-2000): 205-219.

Mason, Haydn. "Voltaire et le conte philosophique". Revue Internationale de Philosophie 48.187 (1994): 55-64.

Mejía Macía, Sergio. Cartografía en la tormenta. Los mapas de Vicente Talledo y Rivera (1758-1820) entre España y el Nuevo Reino de Granada en la Era de las Revoluciones. [En prensa].

Múnera, Alfonso. El fracaso de la nación. Región, clase y raza en el Caribe colombiano (1717-1821). Bogotá:Banco de la República / El Áncora Editores, 1998.

Muñoz Larrea, Enrique. "El teniente general Don Toribio Montes Caloca y Pérez". Boletín de la Academia Nacional de Historia LXXXVIII.184 (2010): 175-183.

Nessler, Graham Townsend. “A Failed Emancipation? The Struggle for Freedom in Hispaniola during the Haitian Revolution, 1789-1809”. Tesis de doctorado en Historia, University of Michigan, 2011.

Niklaus, Robert. "Diderot et le conte philosophique". Cahiers de l'Association Internationale des Études Françaises 13 (1961): 299-315.

Parra Pérez, Caracciolo. Historia de la primera república de Venezuela. Tomo 2. Caracas: Academia Nacional de la Historia, 1959.

Restrepo, José Manuel. Historia de la revolución de la República de Colombia en la América Meridional. Tomo 1. Besanzón: Imprenta de José Jacquin, 1858.

Rodríguez, Jaime. “Toribio Montes y las primeras elecciones populares en Quito”. Boletín de la Academia Nacional de la Historia XC.187 (2012): 77-104.

Rodríguez Villa, Antonio. El teniente general don Pablo Morillo, primer conde de Cartagena, marqués de la Puerta (1778-1837). 4 volúmenes. Madrid: Establecimiento tipográfico de Fortanet, 1910.

Sevilla Naranjo, Alexandra Rosita. “Al mejor servicio del Rey”. Fidelismo, realismo y contrarrevolución en la Audiencia de Quito entre 1809 y 1822". Tesis de doctorado en Historia de los Andes, Facultad Latinoamericana de Ciencias Sociales, 2017.

Stoan, Stephen K. Pablo Morillo and Venezuela, 1815-1820. Columbus: Ohio State University Press, 1974.

Uslar Pietri, Juan. Historia de la rebelión popular de 1814. Contribución al estudio de la historia de Venezuela. París: Ediciones Soberbia, 1954. 